Arq. Bras. Med. Vet. Zootec., v.69, n.3, p.742-750, 2017

\title{
Resíduo úmido de cervejaria na terminação de cordeiros em confinamento e seus efeitos sobre as características da carcaça e dos componentes não carcaça
}

[Wet brewery residue in the finishing of feedlot lambs and its effects on the carcass characteristics and non-carcass components]

\author{
S. Carvalho ${ }^{1}$, M.F. Frasson ${ }^{2}$, F.S.B. Simões ${ }^{2}$, G.M.C. Bernardes ${ }^{2}$, R.R. Simões ${ }^{2}$, L. Griebler ${ }^{2}$, \\ A.C.R.S. Pellegrin ${ }^{2}$, A.M. Menegon ${ }^{3}$, L.S. Deponti ${ }^{3}$, M.M. Severo ${ }^{3}$, V.L. Mello ${ }^{3}$ \\ ${ }^{1}$ Universidade Federal de Santa Maria - Santa Maria, RS \\ ${ }^{2}$ Aluno de pós-graduação, Universidade Federal de Santa Maria - Santa Maria, RS \\ ${ }^{3}$ Aluno de graduação, Universidade Federal de Santa Maria - Santa Maria, RS
}

\begin{abstract}
RESUMO
O objetivo deste trabalho foi avaliar o efeito de níveis crescentes de substituição da silagem de sorgo por resíduo úmido de cervejaria sobre as características da carcaça e dos componentes não carcaça de cordeiros terminados em confinamento. Foram utilizados 24 cordeiros machos, não castrados, oriundos de parto simples e mantidos em baias individuais. Os tratamentos foram constituídos por quatro níveis de substituição de silagem de sorgo por resíduo úmido de cervejaria, sendo: $0 \%$; 33,5\%; 66,5\% e $100 \%$ de substituição. Utilizou-se uma relação volumoso:concentrado de 50:50, com base na matéria seca. $\mathrm{O}$ concentrado era constituído por milho desintegrado, farelo de soja e mistura mineral. As dietas eram isoproteicas, contendo $18,81 \%$ de proteína bruta. Os cordeiros foram abatidos quando atingiram o escore de condição corporal estabelecido em 3 (escala de 1 a 5). As características de carcaça analisadas não foram influenciadas significativamente $(\mathrm{P}>0,05)$ pela substituição de silagem de sorgo por resíduo úmido de cervejaria, sendo obtidos valores médios de $18,92 \mathrm{~kg}$ para peso de carcaça quente, 18,22 kg para peso de carcaça fria, $47,03 \%$ para rendimento de carcaça quente, $45,29 \%$ para rendimento de carcaça fria e $3,41 \%$ para índice de quebra ao resfriamento. Quanto às proporções dos diferentes cortes comerciais avaliados, em relação ao peso de carcaça fria, foram verificados valores médios de 31,86\% para perna, $18,12 \%$ para paleta, $39,46 \%$ para costilhar e $9,08 \%$ para pescoço. As proporções de diafragma, omaso cheio e omaso vazio, em relação ao peso vivo ao abate dos cordeiros, diminuíram linearmente $(\mathrm{P} \leq 0,05)$. As demais variáveis dos componentes não carcaça avaliadas não foram influenciadas $(\mathrm{P}>0,05)$ pelos níveis de resíduo úmido de cervejaria das dietas. Pode-se recomendar o uso de resíduo úmido de cervejaria como fonte exclusiva de alimento volumoso quando se utiliza uma relação volumoso:concentrado de 50:50, em base de matéria seca, para terminação de cordeiros em sistema de confinamento.
\end{abstract}

Palavras-chave: carne ovina, rendimento, resíduos agroindustriais, volumoso

\begin{abstract}
The objective of this study was to evaluate the effect of increasing levels of substitution of sorghum silage by wet brewery residue as forage food on carcass characteristics and non-carcass components of lambs finished in feedlot. Twenty four non castrated male lambs, Suffolk breed, single birth were maintained in individual stalls. The treatments consisted of four substitution levels of sorghum silage by wet brewery residue $(0 \%$; $33.5 \%$; $66.5 \%$ or $100 \%$ of substitution). Roughage and concentrate were used at a 50:50 ratio, based on dry matter. The concentrate was composed of ground corn, soybean meal and mineral mixture. The diets were isoproteic containing $18.81 \%$ crude protein. The lambs were slaughtered when they reached the body condition score of 3 (ranging from 1 to 5). The carcass traits were not affected significantly $(P>0,05)$ by substitution of sorghum silage by wet brewery residue. The average values of
\end{abstract}

Recebido em 7 de julho de 2015

Aceito em 24 de agosto de 2016

E-mail: scarvalhoufsm@hotmail.com 
hot carcass weight, cold carcass weight, hot carcass yield, cold carcass yield and cooling weight losses were $18.92 \mathrm{~kg}, 18.22 \mathrm{~kg}, 47.03 \%, 45.29 \%, 3.41 \%$, respectively. The proportion of commercial cuts in relation to the cold carcass weight, was $31.86 \%$ for leg, $18.12 \%$ for shoulder, $39.46 \%$ for ribs and $9.08 \%$ for neck. The proportion of diaphragm, omasum full and empty omasum in relation to body weight at slaughter decreased linearly $(P \leq 0.05)$. The remaining variables of non-carcass components were not affected $(P>0.05)$ by wet brewery residue inclusion. We recommend the use of wet brewery residue as exclusive source of roughage food when using roughage:concentrate at 50:50 ratio on a dry matter basis, for finishing feedlot lambs.

Keywords: meat lamb, yield, agroindustrial residues, roughage

\section{INTRODUÇÃO}

A ovinocultura de corte no Brasil possui alto potencial de crescimento, já que a produção atual de carne ovina não atende a demanda do mercado consumidor. Porém, para produzir com eficiência e gerar um produto de qualidade, há a necessidade de investimentos em animais geneticamente especializados para produção de carne, associados ao uso de tecnologias de produção e alimentação adequadas para esse fim (Brito, 2005).

Salienta-se que, em um sistema de produção de carne ovina, as características quantitativas e qualitativas da carcaça são de fundamental importância (Silva e Pires, 2000). Nesse sentido, faz-se necessária a produção de um animal jovem (cordeiro) que apresente carcaça sem excesso de gordura e uma carne macia e saborosa, bem como atenda a demanda do consumidor.

Contudo, segundo Furusho-Garcia et al. (2005), alguns aspectos ainda prejudicam a produção e a comercialização desse tipo de produto, entre eles encontra-se a estacionalidade da produção, a qual afeta a continuidade da oferta de carne ovina de qualidade ao longo do ano. No entanto, o rompimento dessa estacionalidade pode ser alcançado pelo emprego de tecnologias intensivas de produção, como o caso do uso do confinamento.

Nesse sentido, segundo Sá e Otto de Sá (2013), o confinamento de cordeiros é, sem dúvida, uma importante alternativa para o incremento na oferta regular do produto. O confinamento apresenta alguns benefícios comparados aos sistemas de produção tradicionalmente utilizados. Entre eles, pode-se salientar a melhoria das condições sanitárias dos animais, a maior agilidade do retorno do capital aplicado, a possibilidade de produção de carnes de qualidade durante todo o ano, a redução da idade de abate e a disponibilização de áreas de campo e de forragem das pastagens para as demais categorias do rebanho.

Entretanto, entre os problemas relacionados, na utilização do confinamento para produção de carne ovina, encontram-se os custos de produção, principalmente relacionados à alimentação dos animais, que é o componente mais expressivo no custo total desse sistema. Nesse contexto, surge o interesse pela utilização de resíduos e subprodutos agroindústrias, os quais, de acordo com Santos (2008), devido à crescente industrialização do Brasil, vêm aumentando significativamente a sua produção. Entre esses, encontra-se o resíduo úmido de cervejaria, um subproduto da indústria cervejeira que apresenta elevada qualidade nutricional e grande potencial para a produção animal.

Este resíduo é resultante do processamento inicial da fabricação de cervejas, que gera grande volume durante $\mathrm{o}$ ano todo e pode ser obtido a baixo custo em indústrias cervejeiras. Do ponto de vista nutricional, esse subproduto merece destaque por conter alto teor proteico (Geron $e t$ al., 2008) e um teor de fibra em detergente neutro (FDN) suficiente para manter a quantidade de fibra necessária na dieta dos animais. Isso permite que esse resíduo possa substituir parcialmente, ou totalmente, o alimento volumoso utilizado na dieta de ruminantes.

Outro aspecto importante relacionado com a produção de carne ovina no Brasil é que a carcaça é a principal unidade de comercialização, desprezando-se, normalmente, os componentes não carcaça, os quais, segundo Carvalho et al. (2005a), representam entre 40 e $60 \%$ do peso vivo do animal no momento do abate, sendo a 
sua proporção influenciada, entre outros fatores, pelo tipo de alimentação utilizada na terminação dos animais. Deve-se enfatizar que, de acordo com Osório (1992), muitos desses componentes são comestíveis e poderiam ser comercializados com vistas ao aumento da rentabilidade do sistema de produção utilizado.

Este trabalho foi conduzido com o objetivo de avaliar os efeitos de diferentes níveis de substituição de silagem de sorgo por resíduo úmido de cervejaria, como alimento volumoso, sobre as características da carcaça e dos componentes não carcaça de cordeiros terminados em confinamento.

\section{MATERIAL E MÉTODOS}

O trabalho, em sua fase de campo, foi realizado no Setor de Ovinocultura do Colégio Politécnico da Universidade Federal de Santa Maria (UFSM) e o período de condução do estudo se estendeu de outubro a dezembro de 2013. Tal pesquisa foi aprovada pela Comissão de Ética no Uso de Animais da mesma instituição, protocolo número 037/2014. Em sua fase laboratorial, o trabalho foi desenvolvido no Laboratório de Nutrição Animal da Universidade Federal de Santa Maria, no estado do Rio Grande do Sul.

Foram utilizados 24 cordeiros machos, não castrados, da raça Suffolk, oriundos de parto simples, desmamados com idade média de 60 dias, devidamente vermifugados e vacinados contra clostridioses. Logo após o desmame, os animais foram confinados em baias individuais, totalmente cobertas, com cama de casca de arroz e dimensão de $2 \mathrm{~m}^{2}$ cada. Todas as baias possuíam comedouros e bebedouros individuais, onde foi fornecida a alimentação e a água para os animais. Os cordeiros foram distribuídos em um delineamento experimental inteiramente ao acaso (DIC), com quatro tratamentos, constituídos por diferentes níveis de substituição do alimento volumoso (silagem de sorgo) por resíduo úmido de cervejaria $(0 \% ; 33,5 \%$; $66,5 \%$ ou $100 \%$ de substituição) e seis repetições.

O início do período experimental foi precedido de um período de 10 dias para adaptação dos animais às condições de instalações, alimentação e manejo. $\mathrm{O}$ ensaio de alimentação iniciou após o período de adaptação, estendendo-se até o momento em que cada cordeiro atingia o escore de condição corporal, preestabelecido em 3 (escala de 1 a 5), e, então, foram abatidos.

A dieta total foi fornecida ad libitum, composta por volumoso à base de silagem de sorgo e/ou resíduo úmido de cervejaria, de acordo com o tratamento, e concentrado composto por milho desintegrado, farelo de soja e mistura mineral. Utilizou-se uma relação volumoso:concentrado de 50:50, com base na matéria seca. As dietas foram formuladas para serem isoproteicas, conforme o Nutrient... (2007), para obtenção de $200 \mathrm{~g}$ de ganho de peso diário. A relação entre a silagem de sorgo e o resíduo úmido de cervejaria variou de acordo com o tratamento, em base da matéria seca (MS), de maneira a se atingir o nível de resíduo úmido de cervejaria pretendido para a dieta experimental.

Na Tab. 1, está apresentada a composição químico-bromatólogica dos alimentos utilizados e, na Tab. 2, a proporção dos ingredientes e a composição bromatológica das dietas experimentais.

Ao atingirem o escore de condição corporal preestabelecido, os cordeiros foram submetidos a jejum de sólidos por 14 horas e, em seguida, pesados, insensibilizados e abatidos mediante sangria. No momento de cada abate, foi coletado todo o sangue, e retirada a pele, patas, cabeça, língua, coração, rins, fígado, pulmão+traqueia, esôfago, baço, pâncreas, diafragma, timo, testículos, pênis, bexiga, gordura interna, gordura perirrenal e gordura do coração, os quais foram pesados separadamente. Foram também pesados individualmente o rúmen, retículo, omaso, abomaso, intestino delgado e intestino grosso, sendo esses órgãos pesados cheios. Em seguida, realizou-se o esvaziamento e uma minuciosa lavagem dos diferentes compartimentos, os quais, após escorrimento da água, foram pesados novamente. Depois, foi calculada a porcentagem dos diferentes órgãos internos em relação ao peso vivo dos animais. 
Tabela 1. Teores médios de matéria seca (MS), matéria orgânica (MO), proteína bruta (PB), extrato etéreo (EE), fibra em detergente neutro (FDN), fibra em detergente ácido (FDA), carboidratos totais (CHT), carboidratos não fibrosos (CNF), nutrientes digestíveis totais (NDT), hemicelulose (HEMIC), celulose (CEL), lignina (LDA), cinzas (CIN), cálcio (Ca) e fósforo (P), dos ingredientes utilizados na formulação das dietas experimentais

\begin{tabular}{|c|c|c|c|c|c|c|c|}
\hline $\operatorname{Item}(\%)$ & $\begin{array}{l}\text { Silagem de } \\
\text { sorgo }\end{array}$ & $\begin{array}{l}\text { Resíduo de } \\
\text { cervejaria }\end{array}$ & $\begin{array}{c}\text { Milho } \\
\text { quebrado }\end{array}$ & $\begin{array}{c}\text { Farelo de } \\
\text { soja }\end{array}$ & $\begin{array}{l}\text { Calcário } \\
\text { calcítico }\end{array}$ & $\begin{array}{c}\text { Fosfato } \\
\text { bicálcico }\end{array}$ & Sal comum \\
\hline MS & 32,54 & 27,51 & 88,46 & 87,94 & 100 & 100 & 100 \\
\hline MO & 95,49 & 91,33 & 98,51 & 93,21 & ----- & ----- & ----- \\
\hline PB & 4,25 & 24,44 & 9,64 & 53,07 & ----- & ----- & ----- \\
\hline $\mathrm{EE}$ & 1,40 & 6,68 & 4,07 & 2,11 & ----- & ----- & ----- \\
\hline FDN & 64,47 & 55,98 & 13,98 & 14,62 & ----- & ----- & ----- \\
\hline FDA & 39,2 & 22,51 & 4,44 & 9,86 & ----- & ----- & ----- \\
\hline CHT & 89,84 & 60,21 & 84,80 & 38,03 & ----- & ----- & ----- \\
\hline $\mathrm{CNF}$ & 25,37 & 4,23 & 70,82 & 23,41 & ----- & ----- & ----- \\
\hline $\mathrm{NDT}^{1}$ & 57,23 & 66,12 & 87,24 & 81,54 & ----- & ----- & ----- \\
\hline HEMIC & 25,27 & 33,47 & $n c^{2}$ & $\mathrm{Nc}$ & ----- & ----- & ----- \\
\hline CEL & 31,10 & 14,17 & $\mathrm{Nc}$ & $\mathrm{Nc}$ & ----- & ----- & ----- \\
\hline LDA & 8,10 & 8,34 & $\mathrm{Nc}$ & $\mathrm{Nc}$ & ----- & ----- & ----- \\
\hline CIN & 4,51 & 8,67 & 1,49 & 6,79 & ----- & ----- & 100 \\
\hline $\mathrm{Ca}$ & 0,30 & 0,23 & 0,03 & 0,34 & 34,00 & 22,00 & ----- \\
\hline $\mathrm{P}$ & 0,18 & 0,70 & 0,25 & 0,58 & 0,02 & 19,13 & ----- \\
\hline
\end{tabular}

${ }^{1}$ Valor tabelado (Valadares Filho et al., 2006).

${ }^{2} \mathrm{nc}=$ não calculado.

Tabela 2. Proporção dos ingredientes (\% MS) e composição bromatológica das dietas experimentais

\begin{tabular}{|c|c|c|c|c|}
\hline & \multicolumn{4}{|c|}{ Teor de resíduo de cervejaria (\%) } \\
\hline & 0 & 33 & 66 & 100 \\
\hline \multicolumn{5}{|c|}{ Proporção dos ingredientes (\% MS) } \\
\hline Silagem de sorgo & 50,00 & 33,25 & 16,75 & 0,00 \\
\hline Resíduo de cervejaria & 0,00 & 16,75 & 33,25 & 50,00 \\
\hline Milho quebrado & 18,40 & 26,21 & 33,91 & 41,66 \\
\hline Farelo de soja & 28,10 & 20,31 & 12,63 & 4,85 \\
\hline Calcário calcítico & 1,50 & 1,83 & 2,12 & 2,44 \\
\hline Fosfato bicálcico & 1,00 & 0,65 & 0,34 & 0,05 \\
\hline Sal comum & 1,00 & 1,00 & 1,00 & 1,00 \\
\hline \multicolumn{5}{|c|}{ Composição bromatológica $(\% \mathrm{MS})$} \\
\hline $\mathrm{MS}$ & 60,76 & 59,95 & 59,16 & $5 \overline{8}, 36$ \\
\hline MO & 92,06 & 91,80 & 91,54 & 91,22 \\
\hline PB & 18,81 & 18,81 & 18,81 & 18,81 \\
\hline $\mathrm{EE}$ & 2,04 & 3,08 & 4,10 & 5,14 \\
\hline FDN & 38,92 & 37,45 & 36,00 & 34,52 \\
\hline FDA & 23,19 & 19,97 & 16,80 & 13,58 \\
\hline CHT & 71,21 & 69,91 & 68,63 & 67,28 \\
\hline $\mathrm{CNF}$ & 32,30 & 32,46 & 32,63 & 32,75 \\
\hline NDT & 67,58 & 69,53 & 71,45 & 73,36 \\
\hline MM & 7,94 & 8,20 & 8,46 & 8,78 \\
\hline $\mathrm{Ca}$ & 0,98 & 0,98 & 0,98 & 0,98 \\
\hline $\mathrm{P}$ & 0,49 & 0,49 & 0,49 & 0,49 \\
\hline
\end{tabular}

Durante todo o experimento, o fornecimento dos alimentos foi realizado diariamente, em dois períodos, manhã e tarde, de modo que permitisse aproximadamente $15 \%$ de sobras, visando garantir o consumo voluntário máximo dos animais.
Após cada abate, a carcaça foi pesada individualmente e, em seguida, resfriada por 24 horas em câmara frigorífica, em uma temperatura de $4{ }^{\circ} \mathrm{C}$, e pesada novamente para determinação do peso de carcaça fria. Foram observadas as seguintes características em relação às carcaças dos cordeiros: peso da carcaça quente, peso da carcaça fria, rendimento de carcaça quente, 
rendimento de carcaça fria e índice de quebra ao resfriamento.

$\mathrm{Na}$ carcaça fria de cada animal, foi avaliada subjetivamente a conformação e o estado de engorduramento, segundo Osório et al. (1998). Em seguida, separou-se a carcaça longitudinalmente, em duas metades, com o auxílio de serra elétrica. Na metade esquerda da carcaça, foi obtida a área de olho de lombo pela exposição do músculo Longissimus dorsi após um corte transversal na carcaça, entre a $12^{\mathrm{a}}$ e $13^{\mathrm{a}}$ costelas, traçando o seu contorno em papel vegetal (Müller, 1980). Para determinação e registro da área, foi utilizado o programa SITER 3.1, modelo A2, descrito por Gioto (2001). Na mesma região do músculo, foi tomada a espessura de gordura de cobertura com o uso de paquímetro, e avaliaram-se subjetivamente a textura, o marmoreio e a cor (Osório et al., 1998).

A metade direita da carcaça foi pesada e separada regionalmente, segundo Osório et al. (1998), nos seguintes cortes comerciais: pescoço, paleta, costilhar e perna. Após a separação, os diferentes cortes comerciais foram pesados, e sua porcentagem calculada em relação ao peso da carcaça fria.

O delineamento experimental utilizado foi o inteiramente ao acaso, em que, na avaliação das quatro dietas experimentais, foram utilizadas seis repetições. Após a coleta dos dados, os resultados foram submetidos às análises de variância e de regressão. As equações foram selecionadas com base nos coeficientes de determinação e na significância dos coeficientes de regressão, adotando-se o nível de 5\% de probabilidade e utilizando-se $\mathrm{o}$ teste $\mathrm{t}$ (Statistical..., 2004).

\section{RESULTADOS E DISCUSSÃO}

Em relação às características de carcaça dos cordeiros (Tab. 3), pode-se verificar que nenhuma das variáveis foi influenciada $(\mathrm{P}>0,05)$ pelo nível de inclusão de RUC nas dietas, o que pode ser explicado pelo fato de os animais serem do mesmo genótipo, idade e sexo, além de serem abatidos com pesos vivos semelhantes e com o mesmo grau de acabamento (escore de condição corporal 3). Além disso, havia uma similaridade quanto à composição bromatológica das dietas experimentais, podendo-se afirmar que o uso de resíduo úmido de cervejaria como alimento volumoso em substituição da silagem de sorgo mantém as dietas com propriedades nutricionais adequadas, proporcionando características quantitativas de carcaças semelhantes entre cordeiros confinados.

O valor médio de $18,75 \mathrm{~kg}$ obtido para o peso de carcaça quente encontra-se próximo àquele observado por Carvalho et al. (2005b), os quais avaliaram o desempenho e as características quantitativas da carcaça de cordeiros da raça Suffolk terminados em confinamento e abatidos com peso vivo médio de $41,55 \mathrm{~kg}$, aos 131 dias de idade, e observaram um valor médio de $19,74 \mathrm{~kg}$.

A respeito dos rendimentos de carcaça quente e fria, deve-se enfatizar que esses são fundamentais do ponto de vista produtivo e econômico de um sistema de produção de carne ovina, e um dos fatores que mais exerce influência sobre eles é o conteúdo do trato gastrointestinal dos animais no momento do abate, o qual, por sua vez, é grandemente influenciado pelo conteúdo de fibra da dieta. Nesse sentido, Brochier e Carvalho (2009), ao testarem o efeito de diferentes proporções de resíduo úmido de cervejaria sobre as características da carcaça de cordeiros terminados em confinamento, observaram redução linear para os rendimentos de carcaça quente e fria à medida que se aumentava o teor de RUC nas dietas. Contudo, esses autores testaram o RUC em substituição ao alimento concentrado e atribuíram o resultado obtido ao aumento do teor de FDN das dietas experimentais, que passou de $29,42 \%$ para dieta com $0 \%$ de RUC para $54,63 \%$ para o nível de $100 \%$ de substituição. Já no presente estudo, o RUC foi testado como alimento volumoso e, uma vez que esse apresenta valores de FDN próximos ao da silagem de sorgo, à medida que se aumentou o nível de substituição, houve uma manutenção na proporção de fibra nas dietas, aspecto determinante para que não houvesse prejuízo em relação aos rendimentos de carcaça dos animais. 
Tabela 3. Valores médios para peso vivo ao abate e para as características da carcaça dos cordeiros, de acordo com os diferentes níveis de inclusão de resíduo úmido de cervejaria como alimento volumoso das dietas

\begin{tabular}{|c|c|c|c|c|c|c|}
\hline & \multicolumn{4}{|c|}{ Teor de resíduo de cervejaria $(\%)$} & \multirow{2}{*}{$\begin{array}{l}\text { Equação de } \\
\text { regressão }^{1}\end{array}$} & \multirow[b]{2}{*}{$\operatorname{Pr}>F$} \\
\hline & 0 & 33 & 66 & 100 & & \\
\hline PVA (kg) & 39,33 & 40,50 & 42,20 & 38,97 & $\overline{\mathrm{Y}}=40,25$ & 0,9467 \\
\hline PCQ (kg) & 18,15 & 18,98 & 19,98 & 18,58 & $\bar{Y}=18,75$ & 0,4661 \\
\hline $\mathrm{PCF}(\mathrm{kg})$ & 17,55 & 18,09 & 19,33 & 17,90 & $\overline{\mathrm{Y}}=18,11$ & 0,5028 \\
\hline RCQ (\%) & 46,28 & 46,80 & 47,38 & 47,67 & $\bar{Y}=46,84$ & 0,0823 \\
\hline $\mathrm{RCF}(\%)$ & 44,75 & 44,66 & 45,83 & 45,90 & $\overline{\mathrm{Y}}=45,24$ & 0,1260 \\
\hline $\mathrm{IQ}(\%)$ & 3,31 & 3,36 & 3,27 & 3,69 & $\bar{Y}=3,41$ & 0,4394 \\
\hline CCAR (1-5) & 3,04 & 3,08 & 3,25 & 2,75 & $\bar{Y}=3,01$ & 0,4828 \\
\hline EENG (1-5) & 3,00 & 3,29 & 3,58 & 3,25 & $\bar{Y}=3,27$ & 0,2993 \\
\hline $\mathrm{AOL}\left(\mathrm{cm}^{2}\right)$ & 15,45 & 15,20 & 16,80 & 16,45 & $\bar{Y}=15,96$ & 0,2662 \\
\hline EGOR (mm) & 2,16 & 2,41 & 3,33 & 2,25 & $\bar{Y}=2,56$ & 0,6440 \\
\hline TEXT (1-5) & 3,25 & 3,08 & 3,25 & 3,25 & $\bar{Y}=3,24$ & 0,9500 \\
\hline MARM (1-5) & 2,41 & 2,25 & 2,25 & 2,33 & $\bar{Y}=2,32$ & 0,8133 \\
\hline COR (1-5) & 3,33 & 3,25 & 3,58 & 3,58 & $\bar{Y}=3,43$ & 0,1982 \\
\hline
\end{tabular}

$\mathrm{PVA}=$ peso vivo de abate; $\mathrm{PCQ}=$ peso da carcaça quente; $\mathrm{PCF}$ = peso da carcaça fria; $\mathrm{RCQ}=$ rendimento da carcaça quente; $\mathrm{RCF}=$ rendimento da carcaça fria; $\mathrm{IQ}=$ índice de quebra ao resfriamento; CCAR = conformação da carcaça; $\mathrm{EENG}=$ estado de engorduramento; $\mathrm{AOL}=$ área de olho de lombo; EGOR = espessura de gordura; $\mathrm{TEXT}=$ textura; MARM $=$ marmoreio; $\mathrm{COR}=$ cor .

${ }^{1} \mathrm{RC}=$ nível de substituição do volumoso da dieta por resíduo de cervejaria.

Quanto ao índice de quebra ao resfriamento (IQ), deve-se enfatizar que esse depende, em grande parte, do teor de gordura existente na carcaça e da proteção que essa proporciona a ela e que quanto menor for esse percentual, maior é a probabilidade de que as carcaças tenham sido manejadas de forma adequada (Fernandes et al., 2008). De acordo com Lima et al. (2013), os valores de perdas por resfriamento observados neste estudo ( $3,41 \%$, em média) estão dentro dos níveis máximos considerados aceitáveis para cordeiros, que variam de 3 a $4 \%$, demonstrando que o critério de abate estabelecido de escore de condição corporal igual a 3 conferiu adequado grau de acabamento e quantidade de gordura de cobertura (valor médio foi de $2,56 \mathrm{~mm}$ ) satisfatória na carcaça dos animais.

Em relação à área de olho de lombo (AOL), é importante enfatizar, segundo Bonifacino et al. (1979), que essa variável é considerada uma medida representativa da quantidade e distribuição das massas musculares, assim como da qualidade da carcaça e, portanto, quanto maior for a AOL melhor será o resultado obtido. $\mathrm{O}$ valor da AOL não foi influenciado pelo nível de RUC das dietas $(\mathrm{P}>0,05)$ e o valor médio observado de $15,96 \mathrm{~cm}^{2}$ pode ser considerado satisfatório para cordeiros especializados em produção de carne.
As proporções e os pesos dos cortes comerciais realizados na carcaça também não foram influenciados pelos níveis de RUC das dietas em substituição à silagem de sorgo $(\mathrm{P}>0,05)$ para nenhuma das variáveis analisadas (Tab. 4). Os resultados obtidos estão de acordo com Brochier e Carvalho (2009), que, embora trabalhando com animais da raça Texel, avaliaram o efeito de níveis crescentes de RUC na terminação dos cordeiros em confinamento e observaram valores médios de $8,84 \%$ para pescoço, $20,04 \%$ para paleta, 36,31\% para costilhar e $33,62 \%$ para perna.

Em relação aos resultados referentes às proporções dos componentes não carcaça em relação ao peso vivo ao abate dos cordeiros, verifica-se que não houve efeito do nível de RUC $(\mathrm{P}>0,05)$ sobre essas variáveis, exceto para $\mathrm{o}$ diafragma, que diminuiu linearmente (Tab. 5). A similaridade entre os tratamentos com relação a esses componentes do peso vivo avaliados já era esperada, pois os animais apresentavam características semelhantes (genótipo, sexo, idade e peso), bem como o mesmo escore de condição corporal pré-abate. A variável que é distinta e que poderia estar influenciando é a alimentação recebida pelos animais. Uma vez que a proteína bruta, nutriente que mais difere em relação à composição bromatológica da silagem de sorgo e do resíduo úmido de cervejaria, foi corrigida para as dietas serem 
isoproteicas, verifica-se na Tab. 1 que havia pouco diferença em relação à composição bromatológica desses alimentos, o que fez com que o valor nutricional das dietas fosse semelhante, aspecto esse que explica o resultado obtido.

Tabela 4. Valores médios para pesos e porcentagens dos diferentes cortes comerciais da carcaça, de acordo com os diferentes níveis de inclusão de resíduo úmido de cervejaria como alimento volumoso das dietas

\begin{tabular}{|c|c|c|c|c|c|c|}
\hline & \multicolumn{4}{|c|}{ Teor de resíduo de cervejaria $(\%)$} & \multirow{2}{*}{$\begin{array}{l}\text { Equação de } \\
\text { regressão }^{1}\end{array}$} & \multirow[b]{2}{*}{$\operatorname{Pr}>F$} \\
\hline & 0 & 33 & 66 & 100 & & \\
\hline Pescoço $(\mathrm{kg})$ & 0,86 & 0,70 & 0,95 & 0,80 & $\overline{\mathrm{Y}}=0,82$ & 0,8423 \\
\hline Paleta $(\mathrm{kg})$ & 1,54 & 1,67 & 1,68 & 1,67 & $\bar{Y}=1,64$ & 0,3725 \\
\hline Costilhar (kg) & 3,54 & 3,53 & 3,83 & 3,48 & $\bar{Y}=3,59$ & 0,9137 \\
\hline Perna $(\mathrm{kg})$ & 2,93 & 3,01 & 3,20 & 2,94 & $\bar{Y}=3,01$ & 0,7469 \\
\hline Pescoço $(\%)$ & 9,58 & 7,85 & 9,85 & 8,93 & $\bar{Y}=9,05$ & 0,9853 \\
\hline Paleta $(\%)$ & 17,43 & 18,84 & 17,33 & 18,87 & $\bar{Y}=18,12$ & 0,4378 \\
\hline Costilhar (\%) & 39,82 & 39,51 & 39,60 & 38,91 & $\bar{Y}=39,46$ & 0,4428 \\
\hline Perna $(\%)$ & 33,18 & 33,79 & 33,21 & 33,27 & $\bar{Y}=33,36$ & 0,9110 \\
\hline
\end{tabular}

${ }^{1} \mathrm{RC}=$ nível de substituição do volumoso da dieta por resíduo de cervejaria.

Tabela 5. Valores médios para as proporções $(\%)$ dos componentes não carcaça, em relação ao peso vivo ao abate, de acordo com os diferentes níveis de inclusão de resíduo úmido de cervejaria como alimento volumoso das dietas

\begin{tabular}{|c|c|c|c|c|c|c|c|}
\hline & \multicolumn{4}{|c|}{ Teor de resíduo de cervejaria (\%) } & \multirow[t]{2}{*}{ Equação de regressão $^{1}$} & \multirow[b]{2}{*}{$\mathrm{R}^{2}$} & \multirow[b]{2}{*}{$\operatorname{Pr}>\mathrm{F}$} \\
\hline & 0 & 33 & 66 & 100 & & & \\
\hline Cabeça & 3,29 & 3,22 & 3,04 & 3,38 & $\overline{\mathrm{Y}}=3,28$ & ----- & 0,9785 \\
\hline Língua & 0,21 & 0,22 & 0,24 & 0,23 & $\overline{\mathrm{Y}}=0,22$ & ----- & 0,5902 \\
\hline Pul+Traq & 1,36 & 1,30 & 1,31 & 1,39 & $\bar{Y}=1,37$ & ----- & 0,8864 \\
\hline Diafragma & 0,52 & 0,50 & 0,47 & 0,46 & $\hat{\mathrm{Y}}=0,52942-0,00088776 \mathrm{RC}$ & 0,20 & 0,0140 \\
\hline Timo & 0,26 & 0,34 & 0,22 & 0,30 & $\overline{\mathrm{Y}}=0,28$ & ----- & 0,9528 \\
\hline Esôfago & 0,16 & 0,14 & 0,15 & 0,13 & $\overline{\mathrm{Y}}=0,15$ & ----- & 0,2584 \\
\hline Fígado & 1,44 & 1,46 & 1,57 & 1,55 & $\bar{Y}=1,50$ & ----- & 0,1871 \\
\hline Pâncreas & 0,11 & 0,12 & 0,11 & 0,11 & $\overline{\mathrm{Y}}=0,11$ & ----- & 0,5190 \\
\hline Baço & 0,14 & 0,15 & 0,15 & 0,16 & $\overline{\mathrm{Y}}=0,15$ & ----- & 0,1194 \\
\hline Coração & 0,40 & 0,43 & 0,46 & 0,46 & $\overline{\mathrm{Y}}=0,42$ & ----- & 0,0609 \\
\hline Rins & 0,26 & 0,28 & 0,31 & 0,31 & $\overline{\mathrm{Y}}=0,28$ & ----- & 0,1003 \\
\hline Bex. vazia & 0,07 & 0,05 & 0,08 & 0,08 & $\overline{\mathrm{Y}}=0,08$ & ----- & 0,6085 \\
\hline G. renal & 0,37 & 0,35 & 0,40 & 0,39 & $\overline{\mathrm{Y}}=0,37$ & ----- & 0,0726 \\
\hline G. Coração & 0,15 & 0,21 & 0,17 & 0,16 & $\overline{\mathrm{Y}}=0,18$ & ----- & 0,9800 \\
\hline G. interna & 1,43 & 1,41 & 1,74 & 1,59 & $\overline{\mathrm{Y}}=1,47$ & ----- & 0,0724 \\
\hline Testículos & 0,50 & 0,50 & 0,54 & 0,51 & $\overline{\mathrm{Y}}=0,51$ & ----- & 0,9742 \\
\hline Pênis & 0,13 & 0,14 & 0,13 & 0,15 & $\overline{\mathrm{Y}}=0,14$ & ----- & 0,9295 \\
\hline Patas & 2,00 & 2,11 & 1,98 & 2,18 & $\overline{\mathrm{Y}}=2,10$ & ----- & 0,6378 \\
\hline Pele & 11,43 & 11,07 & 11,43 & 11,30 & $\bar{Y}=11,36$ & ----- & 0,9163 \\
\hline Sangue & 4,34 & 4,32 & 4,15 & 4,50 & $\overline{\mathrm{Y}}=4,38$ & ----- & 0,8181 \\
\hline
\end{tabular}

Pul+Traq = pulmão e traqueia; Bex, vazia = bexiga vazia; G. renal = gordura renal; G. coração = gordura do coração; G. interna $=$ gordura interna.

${ }^{1} \mathrm{RC}=$ nível de substituição do volumoso da dieta por resíduo de cervejaria.

Na Tab. 6, estão apresentados os valores médios, em \% do peso vivo ao abate, dos componentes não carcaça relacionados com $o$ trato gastrointestinal dos animais. Pode-se observar que apenas as proporções de omaso cheio e vazio foram influenciadas pelo nível de RUC das dietas e que essas diminuíram linearmente. Esse resultado pode ser explicado pela diminuição da proporção de FDA e, possivelmente, pelo aumento da digestibilidade à medida que se incrementava a proporção de RUC, o que fez com que a permanência desse tipo de alimento nesse compartimento e o seu desenvolvimento fossem menores. Além disso, devido ao menor tamanho de partícula do RUC em relação à silagem de sorgo, provavelmente houve diferença em relação à taxa de passagem do alimento volumoso utilizado, também contribuindo para o resultado obtido. 
Deve-se enfatizar que os componentes do trato gastrointestinal, principalmente com conteúdo, representam uma grande proporção do peso vivo e exercem significativa influência sobre o rendimento de carcaça dos animais. Observa-se que, no presente estudo, a soma de todas as partes do trato gastrointestinal, com conteúdo, representou $23,69 \%$ do peso vivo dos cordeiros no momento do abate; sem conteúdo, 6,34\%, e o conteúdo gastrointestinal total representou, em média, $17,36 \%$ do peso vivo dos animais. Verifica-se que o conteúdo gastrointestinal, o qual, entre outros fatores, é fortemente influenciado pela alimentação recebida pelos animais, é aquele componente que representa, com exceção da carcaça, a maior proporção do peso vivo no momento do abate e, portanto, é importante sua avaliação. Uma vez que esse não foi influenciado pelas dietas, pode-se inferir que a substituição de silagem de sorgo por RUC como alimento volumoso não afeta a proporção do conteúdo gastrintestinal total dos animais no momento do abate e, dessa forma, não exerce influência negativa sobre $o$ rendimento de carcaça, conforme foi verificado no presente estudo.

Quanto aos valores médios observados para as porcentagens de rúmen-retículo, omaso e abomaso, sem conteúdo, em relação ao peso vivo ao abate dos animais, verifica-se que encontramse próximos aos obtidos por Brochier e Carvalho (2008), os quais, ao testarem diferentes níveis de resíduo úmido de cervejaria na terminação de cordeiros Texel em confinamento, obtiveram valores médios de 1,89\% para rúmen-retículo, $0,22 \%$ para omaso, $0,63 \%$ para abomaso, $2,37 \%$ para intestino delgado e $2,19 \%$ para intestino grosso.

Tabela 6. Valores médios para as proporções (\%), com e sem conteúdo, dos componentes do trato gastrointestinal dos cordeiros, de acordo com os diferentes níveis de inclusão de resíduo úmido de cervejaria como alimento volumoso das dietas

\begin{tabular}{|c|c|c|c|c|c|c|c|}
\hline & \multicolumn{4}{|c|}{ Teor de resíduo de cervejaria (\%) } & \multirow[t]{2}{*}{ Equação de regressão $^{1}$} & \multirow[b]{2}{*}{$\mathrm{R}^{2}$} & \multirow[b]{2}{*}{$\operatorname{Pr}>\mathrm{F}$} \\
\hline & 0 & 33 & 66 & 100 & & & \\
\hline RÚMC & 14,39 & 13,99 & 13,74 & 13,43 & $\bar{Y}=13,91$ & ----- & 0,4163 \\
\hline RÚMV & 1,73 & 1,79 & 1,67 & 1,65 & $\bar{Y}=1,71$ & ----- & 0,2165 \\
\hline RETC & 0,46 & 0,46 & 0,47 & 0,37 & $\bar{Y}=0,44$ & ----- & 0,3347 \\
\hline RETV & 0,33 & 0,31 & 0,25 & 0,29 & $\bar{Y}=0,30$ & ----- & 0,3713 \\
\hline OMAC & 0,54 & 0,41 & 0,39 & 0,32 & $\hat{\mathrm{Y}}=0,52981-0,00216 \mathrm{RC}$ & 0,57 & 0,0001 \\
\hline OMAV & 0,26 & 0,23 & 0,22 & 0,20 & $\hat{\mathrm{Y}}=0,28962-0,00060 \mathrm{C}$ & 0,24 & 0,0291 \\
\hline $\mathrm{ABOC}$ & 1,28 & 1,47 & 1,31 & 1,53 & $\overline{\mathrm{Y}}=1,41$ & ---- & 0,4505 \\
\hline $\mathrm{ABOV}$ & 0,49 & 0,50 & 0,46 & 0,47 & $\overline{\mathrm{Y}}=0,48$ & ----- & 0,3627 \\
\hline IDELC & 4,06 & 4,42 & 4,07 & 3,94 & $\overline{\mathrm{Y}}=4,13$ & ----- & 0,4708 \\
\hline IDELV & 2,30 & 2,51 & 2,51 & 2,40 & $\bar{Y}=2,45$ & ----- & 0,8108 \\
\hline IGROC & 3,71 & 3,51 & 3,30 & 3,18 & $\bar{Y}=3,38$ & ----- & 0,0967 \\
\hline IGROV & 1,19 & 1,13 & 1,12 & 1,26 & $\overline{\mathrm{Y}}=1,17$ & ----- & 0,4447 \\
\hline CGTOT & 18,23 & 17,93 & 17,05 & 16,48 & $\overline{\mathrm{Y}}=17,36$ & ----- & 0,1913 \\
\hline
\end{tabular}

RÚMC = rúmen cheio; RÚMV = rúmen vazio; RETC = retículo cheio; RETV = retículo vazio; OMAC = omaso cheio; $\mathrm{OMAV}=$ omaso vazio; $\mathrm{ABOC}=$ abomaso cheio; $\mathrm{ABOV}=$ abomaso vazio; IDELC $=$ intestino delgado cheio; IDELV = intestino delgado vazio; IGROC = intestino grosso cheio; IGROV = intestino grosso vazio; CGTOT = conteúdo gastrintestinal total.

${ }^{1} \mathrm{RC}=$ nível de substituição do volumoso da dieta por resíduo de cervejaria.

\section{CONCLUSÕES}

Com exceção das proporções de diafragma, omaso cheio e omaso vazio, a substituição de silagem de sorgo por resíduo úmido de cervejaria como alimento volumoso não altera a proporção dos componentes não carcaça em relação ao peso vivo dos cordeiros. As características na carcaça desses cordeiros também não apresentaram alterações, podendo-se recomendar o uso desse resíduo como fonte exclusiva de alimento volumoso, quando se utiliza uma relação volumoso:concentrado de 50:50, em base de matéria seca, para terminação de cordeiros em sistema de confinamento, sem que ocorram prejuízos em relação às características de carcaça dos animais. 


\section{REFERÊNCIAS}

BONIFACINO, L.; KREMER, R.; ORLANDO, D. et al. Estudio comparativo de corderos Corriedale y Corriedale por Texel. 2. Pesos al nascer, ganancias diarias y caracteristicas de la carcasa. Rev. Vet., v.70, p.63-71, 1979.

BRITO, R.A.M. Desempenho, características de carcaça e composição centesimal da carne de borregos de dois genótipos criados em regime de confinamento. 2005. 103f. Dissertação (Mestrado em Ciência Animal) - Universidade Federal de Goiás, Goiânia, GO.

BROCHIER, M.A.; CARVALHO, S. Aspectos ambientais, produtivos e econômicos do aproveitamento de resíduo úmido de cervejaria na alimentação de cordeiros em sistema de confinamento. Rev. Cienc. Agrotec., v.33, p.1392-1399, 2009.

BROCHIER, M.A.; CARVALHO, S. Peso e rendimento dos componentes do peso vivo de cordeiros terminados em confinamento com dietas contendo proporções crescentes de resíduo úmido de cervejaria. Arq. Bras. Med. Vet. Zootec., v.60, p.12131218,2008

CARVALHO, S.; PIVATO, J.; VERGUEIRO, A. et al. Desempenho e características quantitativas da carcaça de cordeiros da raça Suffolk, castrados e não castrados, terminados em confinamento. Rev. Bras. Agroc., v.11, p.79-84, 2005b.

CARVALHO, S.; SILVA, M.F.; CERUTTI, R. et al. Desempenho e componentes do peso vivo de cordeiros submetidos a diferentes sistemas de alimentação. Cienc. Rural, v.35, p.650-655, 2005a.

FERNANDES, M.A.M.; MONTEIRO, A.L.G.; POLI, C.H.E.C. et al. Características das carcaças e componentes do peso vivo de cordeiros terminados em pastagem ou confinamento. Acta Sci. Anim. Sci., v.30, p.75-81, 2008.

FURUSHO-GARCIA, I.F.; PEREZ, J.R.O.; PEREIRA, I.G. et al. Correlação do índice de muscularidade da perna com tecidos da carcaça de cordeiros Santa Inês puros e cruzas. In: REUNIÃO ANUAL DA SOCIEDADE BRASILEIRA DE ZOOTECNIA, 42., 2005, Goiânia. Anais... Goiânia: SBZ, 2005. 1 CD-Rom.
GERON, L.J.V.; ZEOULA, L.M.; ERKEL, J.A. et al. Coeficiente de digestibilidade e características ruminais de bovinos alimentados com rações contendo resíduo de cervejaria fermentado. Rev. Bras. Zootec., v.37, p.1685-1695, 2008.

GIOTTO, E. Manual siter 3.1. Santa Maria: Universidade Federal de Santa Maria, 2001. 187p.

LIMA, L.D.; RÊGO, F.C.A.; Koetz JUNIOR, C. et al. Interferência da dieta de alto grão sobre as características da carcaça e carne de cordeiros Texel. Semin. Cienc. Agrar., v.34, p.4053-4064, 2013.

MÜLLER, L. Normas para avaliação de carcaça e concurso de carcaças de novilhos. Santa Maria: Universidade Federal de Santa Maria, 1980. 31p.

NUTRIENT Requirements of small ruminants: sheep, goats, cervids, and new worlds camelids. Washington: National Academic Press, 2007. 384p.

OSÓRIO, J.C.S. Estudio de la calidad de canales comercializadas en el tipo ternasco según la procedencia: bases para la mejora de dicha calidad en Brasil. 1992. 335f. Tese (Doutorado em Medicina Veterinária) - Universidade de Zaragoza, Zaragoza, Esp.

OSÓRIO, J.C.S.; OSÓRIO, M.T.M.; JARDIM, P.O. et al. Métodos para avaliação da produção de carne ovina, in vivo, na carcaça e na carne. Pelotas: UFPEL, 1998. 107p.

SÁ, J.L.; OTTO de SÁ, C. Recria e terminação de cordeiros em confinamento. 2013. Disponível em: <http://www.crisa.vet.br/publi_2001/confinamento.ht m>. Acessado em: 22 ago. 2013.

SANTOS, P.P. Uso de casca de soja ou bagaço de cana-de-açúcar na alimentação de ovinos como fonte de fibra em rações contendo alta proporção de concentrado. 2008. 60f. Dissertação (Mestrado em Agronomia) - Escola Superior de Agricultura Luiz de Queiroz, Univgersidade de São Paulo, SP.

STATISTICAL Analysis System. Version 9.0. Cary: SAS Institute, 2004. 5135p.

SILVA, L.F.; PIRES, C.C. Avaliações quantitativas das proporções de osso, músculo e gordura da carcaça em ovinos. Rev. Bras. Zootec., v.29, p.1253-1260, 2000 .

VALADARES FILHO, S.C.; MAGALHÃES, K.A.; ROCHA JUNIOR, V.R. et al. Tabelas brasileiras de composição de alimentos para bovinos. CQBAL 2.0. 2.ed. Viçosa: UFVISuprema Gráfica, 2006. 329p. 